\title{
Electron Bulk Surface Density Effect on Critical Frequency in the F2-Layer
}

\author{
Emmanuel Nanéma ${ }^{1,2}$, Issaka Ouédraogo ${ }^{1}$, Christian Zoundi $^{2}$, Frédéric Ouattara ${ }^{2}$ \\ ${ }^{1}$ Centre National de la Recherche Scientifique et Technologique (CNRST), Institut de Recherche en Sciences Appliquées et \\ Technologies (IRSAT), Ouagadougou, Burkina Faso \\ ${ }^{2}$ Université Norbert ZONGO, Laboratoire de Recherche en Météorologie de l'Espace (LAREME), Koudougou, Burkina Faso \\ Email:nanema_emmanuel@yahoo.fr
}

How to cite this paper: Nanéma, E. Ouédraogo, I., Zoundi, C. and Ouattara, F. (2018) Electron Bulk Surface Density Effect on Critical Frequency in the F2-Layer. International Journal of Geosciences, 9, 572-578. https://doi.org/10.4236/ijg.2018.99033

Received: August 28, 2018

Accepted: September 26, 2018

Published: September 29, 2018

Copyright (C) 2018 by authors and Scientific Research Publishing Inc. This work is licensed under the Creative Commons Attribution International License (CC BY 4.0).

http://creativecommons.org/licenses/by/4.0/ cc) (i) Open Access

\begin{abstract}
Ionosphere layer is the atmosphere region which reflects radio waves for telecommunication. The density in particles in this layer influences the quality of communication. This study deals with the effects of Total Electron Contents (TEC) on the critical frequency of radio waves in the F2-layer. Total Electron Contents parameter symbolizes electron bulk surface density in ionosphere layer. Above critical frequency value in F2 layer (foF2), radio waves pass through ionosphere. The knowledge of this value enables to calibrate transmission frequencies. In this study, we consider TEC effects on foF2 under quiet time conditions during the maximum and the minimum of solar cycle 22, at Ouagadougou station, in West Africa. The study also considers the effects of seasons and the hourly variability of TEC and foF2. This work shows winter anomaly on foF2 and TEC on minimum and maximum of solar cycle phase respectively. Running International Reference Ionosphere (IRI) model enables to carry out the effects of TEC on foF 2 by use of their monthly average values. This leads to a new approach to calibrate radio transmitters.
\end{abstract}

\section{Keywords}

Ionosphere, Total Electron Contents, Critical Frequency in F2-Layer, Solar Cycle Phase, International Reference Ionosphere Model

\section{Introduction}

Many models have been developed to investigate ionosphere layer [1]-[13]. The goal of each model is to get the best approach of the ionosphere and carry out the different parameters of this layer. In this study, we use International Reference Ionosphere (IRI) model to get the Total Electron Contents (TEC) and the 
Critical frequency in the F2-layer (foF2) at Ouagadougou station, characterized by $12.4^{\circ} \mathrm{N}$ and $358.5^{\circ} \mathrm{E}$. Ouagadougou is located in West Africa. IRI is an empirical model of the ionosphere. The model uses data sources and provides different parameters of the ionosphere for a given location. The 2012-version of the model is used in this work to get TEC and foF2 parameters. The Total Electron Contents parameter symbolizes the electron bulk surface density in ionosphere layer. This study considers only quiet time conditions [14]. The five quietest days of the minimum and the maximum of solar cycle 22 are considered to characterize the monthly behavior of the parameters. TEC and foF 2 profiles are obtained at different seasons, using the given values of the parameters by running IRI model.

\section{Study Assumptions}

The study is based on the four characteristic months of the four seasons in selected year. For solar cycle 22, the minimum and the maximum phases are respectively 1985 and 1990 [15]. Each characteristic month in the maximum and the minimum of solar cycle 22 is characterized by the five quietest days.

Running IRI model under its 2012-version enables to carry out TEC and foF2 parameters for a given station. Ouagadougou is closed to the Greenwich Meridian and the Equator. Because of this position, local time at Ouagadougou is given by GMT hour. The hourly values of TEC and foF2 for the five quietest days given by running IRI model under its 2012-version are used to calculate $\mathrm{TEC}_{\text {mean }}$ and foF $2_{\text {mean }}$ values respectively, which are the monthly average values of these parameters.

\section{Results and Discussion}

Figure 1 shows Total electron contents and Critical frequency in F2-layer time profiles during minimum phase (1985) of solar cycle 22. TEC time variation is shown on the primary $\mathrm{Y}$ axis while foF2 time variation is shown on the secondary $\mathrm{Y}$ axis. Panels (a) and (b) are TEC and foF2 seasonal profiles on equinox while panels (c) and (d) represent TEC and foF2 seasonal profiles on solstice. foF2 time variations reproduce mainly "reversed profiles" previously found by [16].

Figure 2 presents Total electron contents and Critical frequency in F2-layer time profiles during maximum phase (1990) of solar cycle 22. On this figure, TEC and foF2 time variations are shown respectively on the primary and the secondary $\mathrm{Y}$ axis. Panels (a') and (b') are TEC and foF2 seasonal profiles on equinox and panels ( $c^{\prime}$ ) and (d') represent TEC and foF2 seasonal profiles on solstice. foF2 time variation reproduce "plateau profiles" on maximum solar cycle phase (1990).

On each phase of solar cycle 22, foF2 values on winter are superior to that on summer. This expresses winter anomaly already found by other authors [17]. This study also shows winter anomaly on TEC profiles during solar maximum 


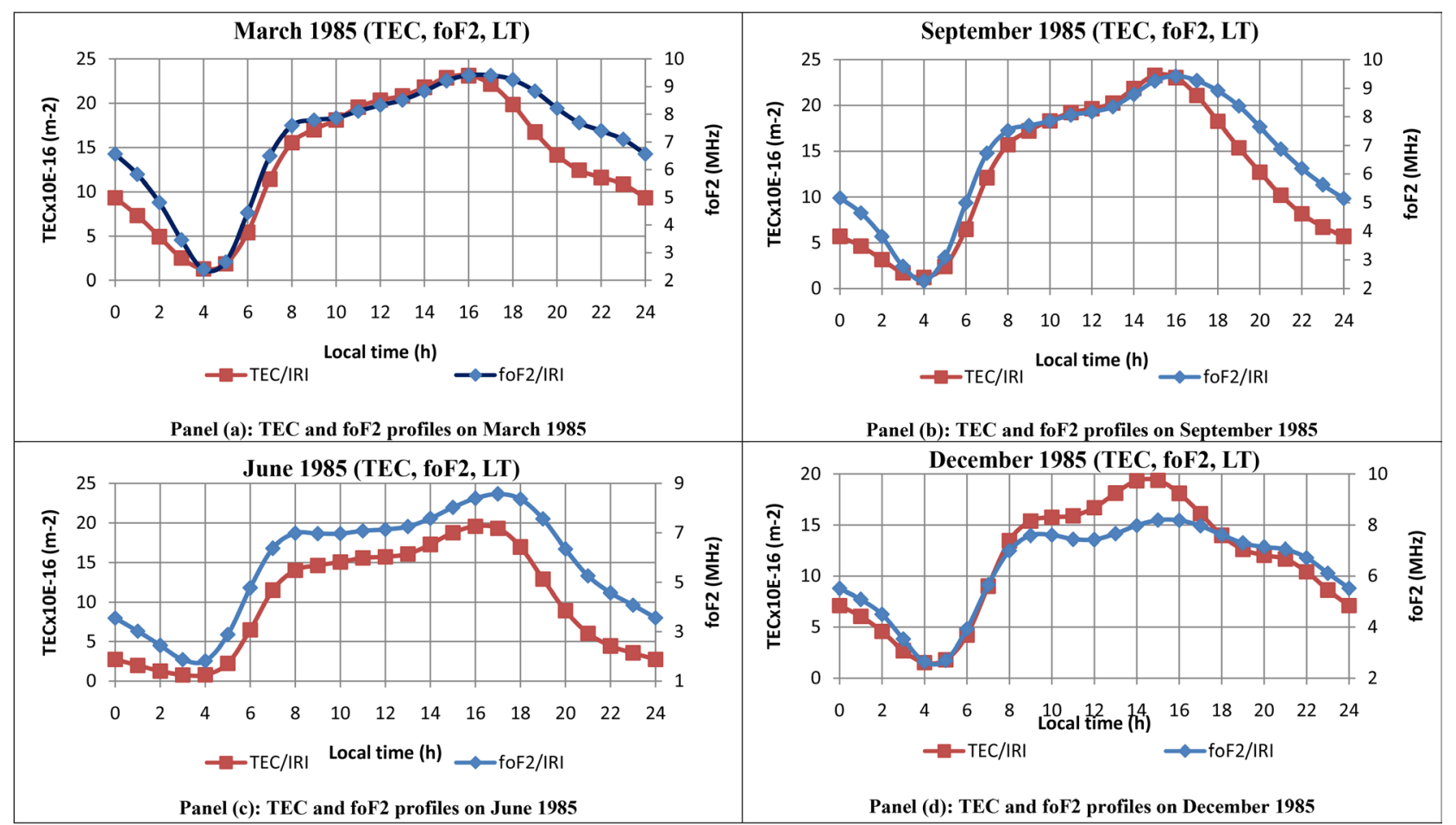

Figure 1. TEC and foF2 profiles during minimum solar cycle phase.

and minimum. This is a new contribution found in this study by running IRI-2012. In Figure 1 and Figure 2, TEC and foF2 time variations present similar trend. The conclusion carried out from this remark is that TEC time variations reproduce "reversed profile" on solar minimum and "plateau profile" on solar maximum.

On each panel of Figure 1 or Figure 2, the knowledge of Total electron contents parameter is determined by a given point on TEC time profile. The vertical line from this point to the $\mathrm{X}$ axis intersects foF2 time variation at a unique point. This intersection point between the vertical line and foF 2 time variation gives foF2 value. This value is the Critical frequency in F2-layer. This method of determining critical frequency in F2-layer value by help of TEC enables to calibrate radio transmitters in telecommunication.

$\mathrm{TEC}_{\text {mean }}$ and foF $2_{\text {mean }}$ values can be expressed by the following equations:

$$
\mathrm{TEC}_{\text {mean }}=\frac{\sum_{i=0}^{i=n-1} T E C_{i}}{n}
$$

and

$$
\mathrm{foF} 2_{\text {mean }}=\frac{\sum_{i=0}^{i=n-1} \mathrm{foF} 2_{i}}{n}
$$

where $\mathrm{TEC}_{\text {mean }}$ and foF $2_{\text {mean }}$ are the mean values of these parameters respectively for each month, $\mathrm{n}$ the number of terms $(n=25) . \mathrm{TEC}_{\mathrm{i}}$ and foF $2_{\mathrm{i}}$ are the values of TEC and foF 2 respectively at $i$ time. 


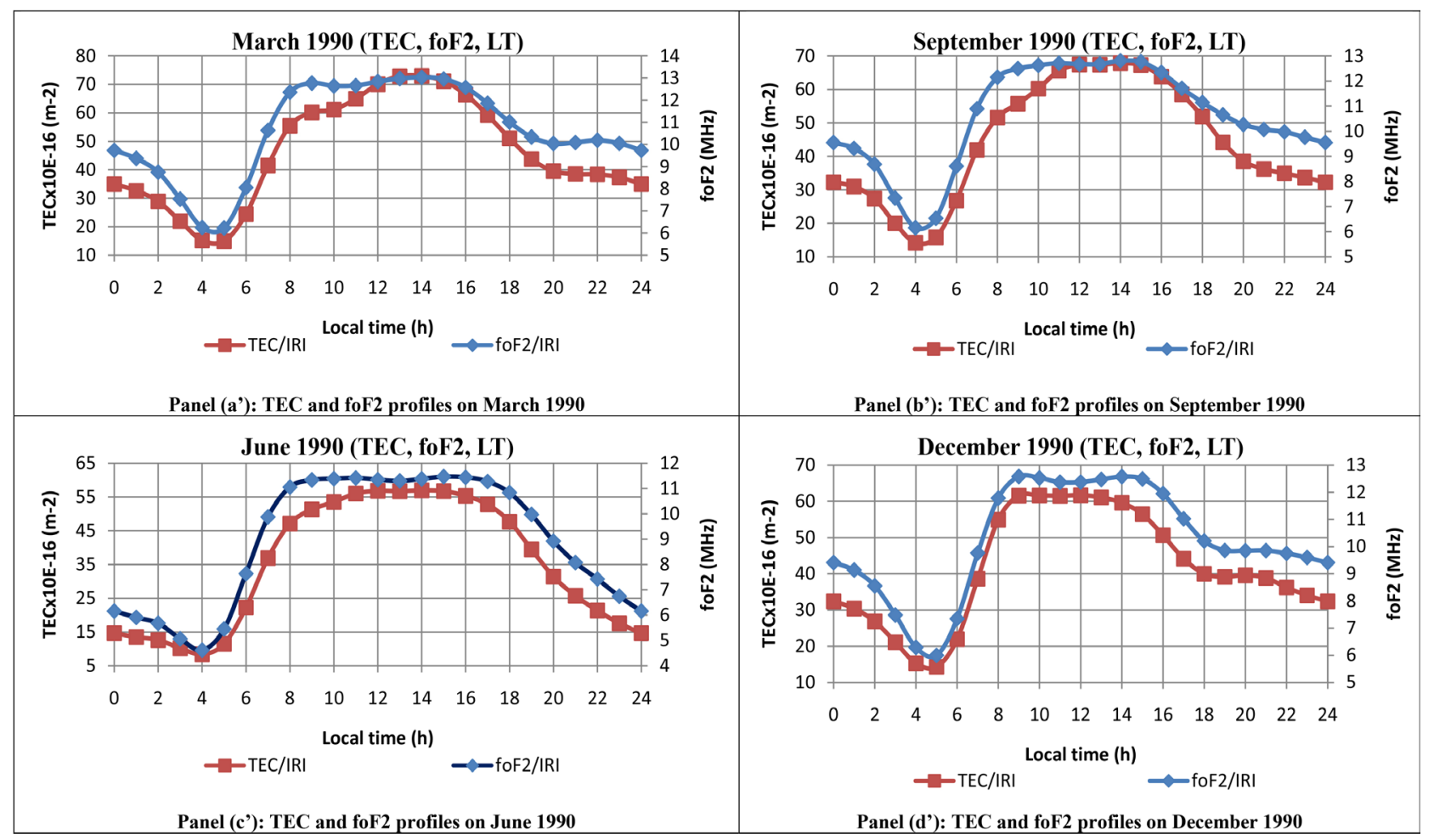

Figure 2. TEC and foF2 profiles during maximum solar cycle phase.

Table 1 presents $\mathrm{TEC}_{\text {mean }}$ and foF $2_{\text {mean }}$ values for different months during the minimum and the maximum of solar cycle 22 .

Table 1 presents the values of $\mathrm{TEC}_{\text {mean }}$ and foF $2_{\text {mean }}$ and the seasonal effect on these parameters. $\mathrm{TEC}_{\text {mean }}$ values on March, June, September and December during solar maximum are almost three times more than that on solar minimum respectively. For foF $2_{\text {mean }}$, the values on solar maximum are almost one and half more than that on solar minimum respectively.

Figure 3 presents the trend of $\mathrm{TEC}_{\text {mean }}$ and foF $2_{\text {mean }}$ on maximum and minimum during solar cycle 22 obtained with the values in Table 1.

Figure 3 presents the trend of $\mathrm{TEC}_{\text {mean }}$ and foF $2_{\text {mean }}$. A decrease of $\mathrm{TEC}_{\text {mean }}$ is followed by a decrease of foF $2_{\text {mean }}$ and conversely. In fact, it is as though the electron bulk surface density, expressed by Total electron contents parameter, is responsible of Critical frequency of F2-layer behavior. Thus, when TEC value increases, radiowaves need to get high values to pass through the F2-layer. Figure 3 shows winter anomaly on foF $2_{\text {mean }}$ and $\mathrm{TEC}_{\text {mean }}$.

\section{Conclusion}

This study highlights that solar maximum TEC and foF2 parameters given by running IRI-2012 are always superior to that of solar minimum. These results have been already found with Thermosphere-Ionosphere General Circulation Model (TIEGCM) developed at High Altitude Observatory (HAO) of National Center for Atmospheric Research (NCAR) and used by [18]. On minimum 
Table 1. TEC $_{\text {mean }}$ and foF $2_{\text {mean }}$ values.

\begin{tabular}{|c|c|c|c|c|c|c|c|c|}
\hline & \multicolumn{8}{|c|}{ Characteristic months of solar cycle 22} \\
\hline & \multicolumn{4}{|c|}{ Minimum (1985) } & \multicolumn{4}{|c|}{ Maximum (1990) } \\
\hline & March 85 & June 85 & Sept. 85 & Dec. 85 & March 90 & June 90 & Sept. 90 & Dec. 90 \\
\hline $\begin{array}{c}\operatorname{TEC}_{\text {mean }} \times \\
10^{-16}\left(\mathrm{~m}^{-2}\right)\end{array}$ & 13.6256 & 9.9864 & 12.5664 & 11.272 & 46.1072 & 34.8608 & 44.2696 & 41.3808 \\
\hline $\begin{array}{c}\text { foF } 2_{\text {mean }} \\
(\mathrm{Mhz})\end{array}$ & 7.0736 & 5.660824 & 6.666032 & 6.321792 & 10.587448 & 8.877976 & 10.540704 & 10.186752 \\
\hline
\end{tabular}

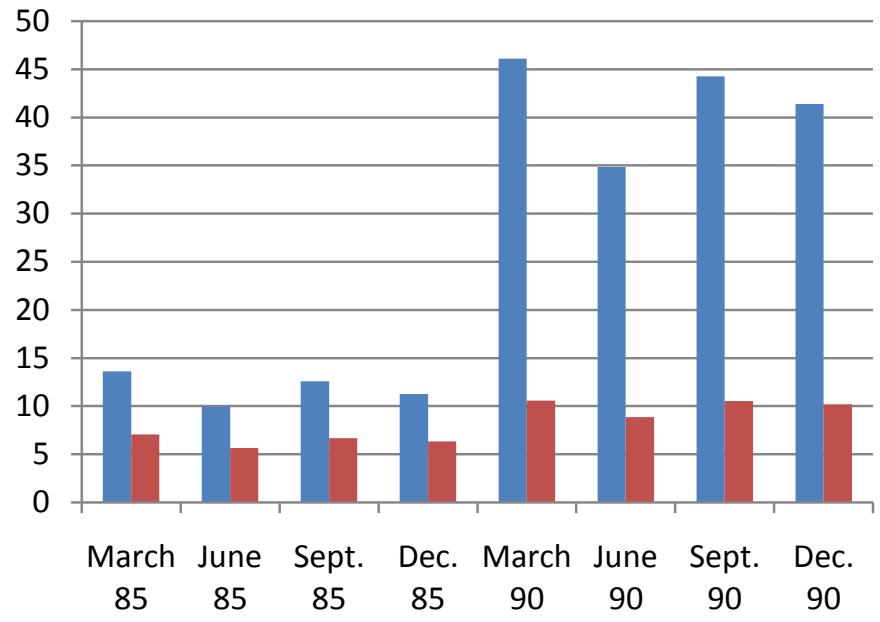

TECmean foF2mean

Figure 3. Trend of $\mathrm{TEC}_{\text {mean }}$ and foF $2_{\text {mean }}$.

phase, TEC $_{\text {mean }} \times 10^{-16}\left(\mathrm{~m}^{-2}\right) \in[9.9864,13.6256]$ and

foF $2_{\text {mean }}(\mathrm{MHz}) \in[5.660824,7.0736]$ while on maximum phase,

$\mathrm{TEC}_{\text {mean }} \times 10^{-16}\left(\mathrm{~m}^{-2}\right) \in[34.8608,46.1072]$ and

foF $2_{\text {mean }}(\mathrm{MHz}) \in[8.877976,10.587448]$. Running IRI model under its 2012 ver-

sion reproduces "reversed profiles" on minimum and "plateau profile" on maximum solar cycle phases on foF2 time profiles. It also reproduces winter anomaly on foF 2 profiles. These different conclusions have been previously found by other authors. The closed link between foF 2 and TEC time variations is carried out. Winter anomaly on TEC parameter during both solar minimum and maximum is a new contribution carried out from this study. The study shows total electron contents effect on critical frequency of radio waves in the ionosphere layer. It brings a new approach to calibrate radio transmitter for telecommunication using total electron contents value according to the season. This approach for radio waves calibration differs from the usual method using time zone adjustment of transmitters.

\section{Conflicts of Interest}

The authors declare no conflicts of interest regarding the publication of this paper. 


\section{References}

[1] Bittencourt, J.A. and Chryssafidis, M. (1994) On the IRI Model Predictions for the Low-Latitude Ionosphere. Journal of Atmospheric and Solar-Terrestrial Physics, 56, 995-1009. https://doi.org/10.1016/0021-9169(94)90159-7

[2] Bhuyan, P.K. and Borah, R.R. (2007) TEC Derived from GPS Network in India and Comparison with the IRI. Advances in Space Research, 39, 830-840.

https://doi.org/10.1016/j.asr.2006.12.042

[3] Ouattara, F. and Rolland, F. (2011) Variability of CODG TEC and IRI 2001 Total Electron Content (TEC) during IHY Campaign Period (21 March to 16 April 2008) at Niamey under Different Geomagnetic Activity Conditions. Scientific Research and Essays, 6, 3609-3622. https://doi.org/10.5897/SRE10.1050

[4] Sethi, N.K., Dabas, R.S. and Das, R.M. (2007) Diurnal and Seasonal Variations of B0, B1 Parameters during High Solar Activity Period at Low Mid-Latitude and Their Comparison with IRI-2001 Model. Journal of Atmospheric and Solar-Terrestrial Physics, 69, 767-774. https://doi.org/10.1016/j.jastp.2007.01.008

[5] Sethi, N.K., Dabas, R.S. and Vohra, V.K. (2004) Diurnal and Seasonal Variations of HmF2 Deduced from Digital Ionosonde over New Delhi and Its Comparison with IRI 2001. Annals of Geophysics, 22, 453-458.

https://doi.org/10.5194/angeo-22-453-2004

[6] Richmond, A.D., Matsushita, S. and Tarpley, J.D. (1976) On the Production Mechanism of Electric Currents and Fields in the Ionosphere. Journal of Geophysical Research, 81, 547-555. https://doi.org/10.1029/JA081i004p00547

[7] Jin, S. and Park, J.U. (2007) Ionospheric Tomography: A Comparison with the IRI-2001 Model over South Korea. Earth Planet Space, 59, 287-292.

https://doi.org/10.1186/BF03353106

[8] Pedatella, N.M., Forbes, J.M., Maute, A., Richmond, A.D., Fang, T.-W., Larson, K.M. and Millward, G. (2011) Longitudinal Variations in the F Region Ionosphere and the Topside Ionosphere-Plasmasphere: Observations and Model Simulations. Journal of Geophysical Research, 116, A12309. https://doi.org/10.1029/2011JA016600

[9] Qian, L., Burns, A.G., Chamberlin, P.C. and Solomon, S.C. (2010) Flare Location on the Solar Disk: Modeling the Thermosphere and Ionosphere Response. Journal of Geophysical Research, 115, A09311. https://doi.org/10.1029/2009JA015225

[10] Roble, R.G., Ridley, E.C., Richmond, A.D. and Dickinson, R.E. (1988) A Coupled Thermosphere/Ionosphere General Circulation Model. Geophysics Research Letter, 15, 1325. https://doi.org/10.1029/GL015i012p01325

[11] Weimer, D.R. (2005) Improved Ionospheric Electrodynamic Models and Application to Calculating Joule Heating Rates. Journal of Geophysical Research, 110, A05306. https://doi.org/10.1029/2004JA010884

[12] Wang, W., Wiltberger, M., Burns, A.G., Solomon, S.C., Killeen, T.L., Maruyama, N. and Lyon, J.G. (2004) Initial Results from the Coupled Magnetosphere-IonosphereThermosphere Model: Thermosphere-Ionosphere Responses. Journal of Atmos pheric and Solar-Terrestrial Physics, 66/15-16, 1425. https://doi.org/10.1016/j.jastp.2004.04.008

[13] Richmond, A.D., Ridley, E.C. and Roble, R.G. (1992) A Thermosphere/Ionosphere General Circulation Model with Coupled Electrodynamics. Geophysics Research Letter, 19, 601. https://doi.org/10.1029/92GL00401

[14] Ouattara, F. and Nanéma, E. (2014) Quiet Time foF2 Variation at Ouagadougou 
Station and Comparison with TIEGCM and IRI-2012 Predictions for 1985 and 1990. Physical Science International Journal, 4, 892-902.

[15] Ouattara, F. and Nanéma, E. (2011) hmF2 Quiet Time Variations at Ouagadougou and Comparison with IRI-2012 and TIEGCM Predictions during Solar Minimum and Maximum. Archives of Applied Science Research, 5, 55-61.

[16] Vassal, J. (1982) La variation du champ magnétique et ses relations avec l'électrojetéquatorial au Sénégal oriental. Annales de Géophysique, 38, 347-355.

[17] Nour, A.M., Frédéric, O., Louis, Z.J., Frédéric, G.A.M., Emmanuel, N. and François, Z. (2015) Statistical Study of foF2 Diurnal Variation at Dakar Station from 1971 to 1996: Effect of Geomagnetic Classes of Activity on Seasonal Variation at Solar Minimum and Maximum. International Journal of Geosciences, 6, 201-208. https://doi.org/10.4236/ijg.2015.63014

[18] Nanema, E., Gnabahou, D.A., Zoundi, C. and Ouattara, F. (2018) Modeling the Ionosphere during Quiet Time Variation at Ouagadougou in West Africa. International Journal of Astronomy and Astrophysics, 8, 163-170.

https://doi.org/10.4236/ijaa.2018.82011 